\title{
Solid waste management in Kulhudhuffushi, Maldives; Most suitable solution for the Crisis
}

\section{Saifulla Aboobakur ${ }^{1}$, M.B Samarakoon ${ }^{2}$}

\author{
${ }^{1}$ Undergraduate, Department of Civil Engineering, General Sir John Kotelawala Defence University, Sri Lanka \\ Email: saifullaaboobakur@gmail.com \\ ${ }^{2}$ Senior Lecturer Faculty of Engineering, General Sir John Kotelawala Defence University, Sri Lanka \\ Email: methsiris@gmail.com
}

\begin{abstract}
This research is to find the most suitable, applicable and practical solution for the collection, transfer, transport and disposal of municipal solid waste in Hdh.Kulhudhuffushi of Republic of Maldives. This research was aimed to find the most suitable solid waste disposal method, along with the proper collection system, transfer and transport mechanism. The research covers waste generation sources as, households, businesses, restaurant and institutions. The annual maximum waste generation was from households, with 4,107 tonnes of waste per year. Average generation rate was 1.13 - $1.55 \mathrm{~kg}$ per capita per day. The total waste generation rate was 5,643.89 tonnes per year. The highest portion of solid waste was kitchen/food waste with 2,181.93 tonnes per year. The total composition of biodegradable and non-biodegradable waste was $68 \%$ and $32 \%$ respectively. Hence, method of composting was selected over incineration, due to the huge (98\%) amount of moisture and low volatility of biodegradable waste. Since, the land ok Kulhudhuffushi dump site is smaller in size mechanical composting was preferred. The non-biodegradable waste would be stored in bunkers and transferred to the incineration plant quarterly each year. The collection facility would be separate collection with rear loading dump trucks as well as multi compartment dump trucks scheduled to collect waste twice a week. For the efficiency of the collection process the town was divided in to three zones with equal number of households, and thereby the collection crew can complete one round of collection within three days' time.
\end{abstract}

Keywords - biodegradable, collection, generation, highest portion, transferred

\section{INTRODUCTION}

Waste management (more specifically solid waste management) is a field with a large scope. This research is completely focused on to population in addition to municipal solid waste types. Therefore, this research would purely focus on solid waste management of Kulhudhuffushi. Though Kulhudhuffushi is one of the largest islands of Maldives, it has a land area of roughly $3.5 \mathrm{~km} 2$. In the early ages there is no specific areas in the town marked as land fill zones or dump sites for the citizens, to collect dispose the waste. As a result, from the earliest of the times people used to dump the waste near the sea shore and to the ocean. Kulhudhuffushi has a small land mass and with a growing population the area considered as the dump site in the year 2000 was 17,010 square meters. Now this small area of land is over filled and in-need of renovation.

Solid Waste Management one of the greatest challenges confronted by the developed as well as developing countries. Improper techniques used for the handling and lack of waste handling facilities have adverse effect on the environment in addition to the people around. Similarly, the issue of Solid Waste Management is one of the major concerns in the town of Kulhudhuffushi with no proper facilities and techniques to deal with solid waste. Therefore, what would be the most suitable solution for solid waste issue in Kulhudhuffushi?

The aim of this research is to find the most suitable, applicable and practical solution for the collection, transfer, transportation and disposal of solid waste in the town of Kulhudhuffushi of Republic of Maldives.

1. To identify the problems related to Solid Waste Management in Kulhudhuffushi

2. To propose possible solid waste management solutions which could be implemented in Kulhudhuffushi

3. To propose the most suitable collection system for Kulhudhuffushi

4. To propose most convenient waste transportation method for Kulhudhuffushi

\section{LITERATURE REVIEW}

Any material which is thrown away or discarded as useless and unwanted could be considered as solid waste. When 
solid waste disposal process is not maintained or managed, it would lead to air, water and land pollution resulting in various unhealthy conditions. Solid waste can be classified to Municipal, Industrial, Hazardous, Agricultural and Biomedical Solid Waste. Each of these types of solid waste has to be treated differently as the composition of the waste changes. [1]

\subsection{Solid Waste Terminology}

The term Municipal Solid Waste (MSW) is generally used to describe most of the non-hazardous solid waste. [2] Refuse and Trash are the main two components of Municipal Solid Waste. Refuse consists of garbage and rubbish. Garbage contains putrescible or highly decomposable food waste. Hence, garbage cause attracts flies and other insect trouble and also ferment readily resulting in the production of unpleasant odours, hence needing special attention. [3] Rubbish is mostly dry, nonputrescible materials. Rubbish is frequently responsible for the creation of nuisance when it is scattered by careless handling or by wind. [3] Trash is the bulky waste materials that generally requires special handling and is therefore, not collected on a routine basis. [3]

\subsection{Quantity and Composition of Waste}

Quantity of solid waste the amount of waste by weight or volume generated per capita per year. The composition of waste is the amount of different types of waste present in the municipal solid waste. Information regarding the weight, volume and composition of municipal solid waste is necessary for the proper planning, design and operation of collection and disposal facilities. Weight and volume play a crucial role in determining the size of collection vehicles as well as the sizes of the disposal plants. Moreover, the composition is vital to determine the method of disposal. [4] In the context of the Maldives, waste generation was estimated between $2 \mathrm{~kg}-5 \mathrm{~kg}$ per capita per day. Municipal solid waste contains a wide variety of materials, some which could be burnt while others cannot. A portion of MSW can also be recovered and a percentage of it been recyclable.

\subsection{Moisture Content and The Density of Solid Waste}

Knowledge of the moisture content of the waste is important when the waste is used for energy recovery. The knowledge of moisture contact would provide the amount of heat the waste can produce. [5] Moisture content also plays a key role when the waste is subjected to anaerobic decomposition in sanitary landfills. To subject the organic matter to composting and anaerobic digestion, the water content must be put at the optimum. [5] The moisture content is expressed wet and dry ( $\mathrm{Pw}$ and $\mathrm{Pd}$ respectively) percentage.

$P_{w}=\frac{W}{S_{w}} \times 100$

$P_{w}=\frac{W}{S_{w}} \times 100$

Where, $\mathrm{W}$ is the mass of the moisture, $\mathrm{Sd}$ the mass of the dry solid waste and $\mathrm{Sw}$ the mass of the wet solid waste.

The most important use of knowledge of the density of solid waste is the determination of its compacted volume. By the knowledge of the compacted density, the volume of landfill space or the storage space can (a compacted volume) can be calculated easily. Compacted volume is also used to determine the size of the collection trucks. [5] Compactor machines compaction rations can vary from 2 to 4 . In landfills the compaction ration can vary from 297 to $891 \mathrm{~kg} / \mathrm{m} 3$. Generally, 475 to $594 \mathrm{~kg} / \mathrm{m} 3$ can be achieved in landfills with a moderate compaction effort, while a density of $297 \mathrm{~kg} / \mathrm{m} 3$ can be achieved from a poor compacted landfill. [5]

\subsection{Solid Waste Collection}

The total process of Municipal Solid waste management is divided in Collection, Transfer, Transport and Disposal. About two third of the total cost of solid waste management is covered for waste collection. Collection system of solid waste can be divided in primary collection and secondary collection. Primary collection involves the collection of solid waste from house to house, the point of waste generation to a suitable nearly common location known as the transfer station. From the transfer station the waste the waste would be further collected and transported to the point of disposal. The transfer of solid waste from the transfer station to the disposal site is known as the secondary collection. [3] The process of primary collection is subcategorized into four categories, communal storage, block collection, Kerbside collection and door-to-door collection. [4]

\subsection{Transport of Solid Waste}

Transportation of solid waste involves the transfer of waste form the transfer station to the disposal site. The process involves heavy motor vehicles and is necessary when the source of the waste is extremely far from the final disposal site. [3]

\subsection{Chemical and Energy Properties of MSW}

The energy content increases with the amount of volatile matter present in the waste. The energy content of solid 
waste is the heat of combustion released when the waste is burned. Hence, there are two types of heat due to combustion. They are known as higher heat of combustion and lower heat of combustion. [2] The higher heat of combustion includes the heat of vaporization of water. Lower heat of combustion does not include the heat of vaporization of water.

\subsection{Composting of Municipal Solid Waste}

Composting is the process by which the organic portion of the solid waste is allowed to decompose under carefully controlled conditions in a rather biological process than a chemical process. With proper control of temperature, moisture and aeration, a composting plant is capable of reducing the volume of the raw organic matter by as much as 50 percent. [6] Process of composting stabilizes the waste and produce an end product that can be recycled for beneficial purposes. A complete municipal solid waste composting operation includes sorting and separating, shredding and pulverizing, digestion, product upgrading, and finally marketing.

\subsection{Incineration of Municipal Solid Waste}

Incineration is expensive, primarily because extensive air pollution control equipment is required and it requires high-level technicians and skilled employees for proper operation and maintenance. However, the advantages of the incinerator often outweigh these disadvantages. [4] Incineration is a chemical process in which the combustion potion of the waste is mixed with oxygen, forming carbon dioxide and water. For the complete combustion the waste must be mixed with appropriate volume of air, and a proper temperature must be maintained for a suitable length of time. [3]

Sanitary landfills are simple, cheap, and effective method of waste disposal. Yet, this method may not be suitable for Kulhudhuffushi due to the lack of land shallow water table. Incineration of solid waste suited for towns where land filling is not available. The method of incineration can reduce the garbage volume by $90 \%$. This method is a highly suitable option however, setbacks like high construction and operation costs would be problem to initiate the project. Composting is similar to sanitary land fill but yields a stable end product which is a good soil conditioner and may be used as a base for fertilizers. Therefore, if this system is to be used along with a fertilization or cultivation island it could be beneficial. However, other costs such as transportation of the solid wastes arrives with this method.

\section{METHODOLOGY}

\subsection{Site Selection}

The Journal is published in standard A4 size with a twocolumn layout for text. Diagrams and tables should be in portrait orientation with either one or two column width. As per the Kulhudhuffushi Island Council, there were 2160 households in Kulhudhuffushi, while 1485 households were contributing to the municipal solid waste. The remaining 531 were under construction. In addition to the household, business establishments were key sources contributing to solid waste. There were 205 retail and whole sale business establishments in Kulhudhuffushi.

\subsection{Sample Selection}

The target area for the research was the town of Kulhudhuffushi and the people you were using the municipal solid waste management system of Kulhudhuffushi. Hence, citizens from other island were also given change to participate in the research as the target samples were selected on the basis of households, businesses, restaurants and institutions, rather than individuals. The sample size was selected with following equations, put forward by Professor Othman Alsalloum, of King Saud University, Saud Arabia. The sample size was calculated as by considering the total population as the sum of all the household, businesses, restaurants and the institutions. The total sample received from this figure was then further divided among the different categories (household, businesses, restaurants and the institutions) depending on their ration.

The Minimum Sample Size for Infinite Population (Population Larger Than 10,000)

$n=\frac{Z^{2} P(1-P)}{d^{2}}$

Where;

$$
\begin{aligned}
& \mathrm{n}=\text { Minimum Sample Size for a Large Population } \\
& \mathrm{Z}=\text { Standard Normal Distribution } \\
& \mathrm{P}=\text { Expected Probability } \\
& \mathrm{d}=\text { Maximum Allowable Deviation }
\end{aligned}
$$

The Minimum Sample Size for a Small Population (Population Smaller Than 10,000)

$$
n s p t=\frac{n}{1+\left(\frac{n}{s p z}\right)}
$$

Where; Population

Nspt $=$ Minimum Sample Size for a Small

$\mathrm{n}=$ Minimum Sample Size for a Large Population $\mathrm{spz}=$ Size of the Population 
A total of 264 samples of data was collected from Households, while 27 samples were collected from the business sector. From restaurants and institutions, a total number of 5 and 12 samples were collected respectively. Therefore, the total number of samples collected was well beyond the required minimum sample size. For the collection of data through questionnaires the household were selected on a random basis to get a generalized idea from the whole town.

The method of interviews was be focused on the authorities' such as Kulhudhuffushi Island Council, Kulhudhuffushi Regional Hospital, Waste Management Corporation of Maldives, Fenaka Corporation, Waste collecting personals and Ministry of Environment and Energy. The data collected from the above-mentioned authorities was an added reliability to the data collected from the target groups with the method of questionnaire.

\section{RESULTS AND DISCUSSION}

\subsection{Average Composition of Municipal Solid Waste from Households}

The maximum composition of municipal solid waste from the households were kitchen / food waste. Only a small fraction 2 percent and 3 percent of the household waste was metal and wood respectively. Moreover, 9 percent of the waste was paper and 4 percent of waste being glass. 5 percent and 9 percent of the waste was clothing and plastic materials respectively. The second highest composition of household waste was considered as the other types of waste, consisting of 21 percent of the total solid waste from household. From the figure below, it was clear that the 84 percent of the waste mentioned as others were leaves. In addition to that, diapers, fish waste, rotten fruits and vegetables adds up to the biodegradable potion of the household solid waste. Hence, 97 percent of the waste mentioned as others were biodegradable waste. A total of 78.4 percent of house hold solid waste was biodegradable. That leaves 21.6 percent, roughly one third of the household waste to be non-biodegradable.

\subsection{Average Waste Generation Rate per Households}

The average daily rate of waste generation per house hold on a daily basis was a total average of $7.58 \mathrm{~kg}$ of waste is generated per household. Among which kitchen waste was $3.54 \mathrm{~kg}$ (as it was 47 percent of the total solid waste). Kitchen waste was followed by others category with 1.57 kilograms, which implies 1.32 kilograms of other waste was leaves. Plastic, metal, wood, paper, glass and clothing was $0.72 \mathrm{~kg}, 0.18 \mathrm{~kg}, 0.19 \mathrm{~kg}, 0.66 \mathrm{~kg}, 0.33 \mathrm{~kg}$ and $0.39 \mathrm{~kg}$ respectively. Therefore, $5.91 \mathrm{~kg}$ out of $7.58 \mathrm{~kg}$ of waste generated on a daily basis was biodegradable waste.

\subsection{Average Composition of Municipal Solid Waste from Businesses}

The maximum composition of municipal solid waste from the businesses were paper waste with 34 percent of the total waste composition. Plastic products were the second largest type of waste contributing to municipal solid waste from the restaurants with 22 percent of the total waste. Furthermore, food waste was also quite high in composition with 13 percent. Clothing and wood were with the smallest contribution to municipal solid waste with only 5 percent each. Metal and glass were found to be 10 and 6 percent respectively. Moreover, 5 percent of waste from the businesses were classified as other, and only damaged fruits, vegetable and other food items were included in the category. Therefore, 57 percent of waste from the businesses were biodegradable while 43 percent of the waste generated from the businesses were nonbiodegradable.

\subsection{Average Waste Generation Rate per Business}

The average daily rate of waste generation per business establishments was on a daily basis is a total average of $13.78 \mathrm{~kg}$ of waste is generated per business outlets. Among which $4.67 \mathrm{~kg}$ was paper waste, as it was occupying 34 percent of the total solid waste from business outlets. With the second highest composition, plastic waste generation was $3.01 \mathrm{~kg}$ per day. Kitchen waste was $1.74 \mathrm{~kg}$. Kitchen waste was followed by metal, glass, clothing, wood and others with a weightage of $1.38 \mathrm{Kg}, 0.79 \mathrm{Kg}, 0.73 \mathrm{Kg}$, $0.72 \mathrm{~kg}$ and $0.71 \mathrm{Kg}$ respectively. Therefore, $7.84 \mathrm{~kg}$ of the waste was biodegradable per single business establishment. Which result in only $5.91 \mathrm{~kg}$ of nonbiodegradable waste from each business outlet per day.

\subsection{Average Composition of Municipal Solid Waste from Restaurants}

The maximum composition of municipal solid waste from the restaurants were kitchen and food waste. Plastic products were the second largest type of waste contributing to municipal solid waste from businesses with 19 percent of the total waste. Furthermore, paper was also quite high in composition with 14 percent due to high number of paper serviettes and paper receipts. wood and clothing were having no contribution to the municipal solid waste stream. Glass was with 5 percent contribution to municipal solid, while metal gives a 9 percent contribution due to the tins and cans used in food packaging. Only 1 percent of the total waste generated from the restaurants were considered as others, consisting of dry leaves and garden waste from the tress and small gardens with in the restaurants. Therefore, 67 percent of 
total waste from the restaurants were biodegradable while 33 percent of the waste generated from the businesses were non-biodegradable.

\subsection{Average Waste Generation Rate per Restaurant} On a daily basis a total average municipal solid waste generated per restaurant was found to be 48 kilograms. Among this $24.90 \mathrm{Kg}$ of waste was kitchen and food waste. Second highest waste type was plastic items with $9.10 \mathrm{~kg}$ followed by paper items with $6.80 \mathrm{~kg}$. Metal waste and glass waste are $4.10 \mathrm{~kg}$ and $2.60 \mathrm{~kg}$ per day respectively. As mentioned before, wood and cloth waste were not generated in the restaurants. Therefore, $32.2 \mathrm{~kg}$ of waste on a daily basis was biodegradable waste from a single restaurant. $15.8 \mathrm{Kg}$ of waste from the restaurants were nonbiodegradable.

\subsection{Average Composition of Municipal Solid Waste from Institution}

The above figure represents the percentage composition of municipal solid waste generated on an average basis per single institutions Kulhudhuffushi per day. The largest three categories of solid waste generated from institution includes, paper waste, other types of waste and plastic waste with a waste composition of 36 percent, 27 percent and 23 percent respectively. Other categories of waste were in a small composition. Wood waste was 6 percent of the total waste. Kitchen and food waste along with glass was makes up a waste of only 2 percent each. Metaling waste was observed to be 3 percent and cloth material to be just 1 percent of the total waste. The 27 percent of waste indicated in the other waste category contains 4.5 percent of cardboard and 22.5 percent of dry leaves and garden waste. As a result, only 29 percent of the waste from institutions were non-biodegradable while a whopping 71 percent of waste was biodegradable.

\subsection{Average Waste Generation Rate per Institution}

The average waste generation rate of an institution was 38.58 kilograms per institution per day. Among the $38.58 \mathrm{~kg}$ of daily waste $14.07 \mathrm{~kg}$ was paper waste. Category of others are second in line with $10.24 \mathrm{~kg}$. Others category consists of cardboard, dry leaves and garden waste. Plastic was the third most contributing to the solid waste with 8.84 kilograms. Wood, metal, kitchen food, glass and cloth materials were the lowest by weight with only $2.25 \mathrm{~kg}$, $1.08 \mathrm{~kg}, 0.94 \mathrm{~kg}, 0.85 \mathrm{~kg}$ and $0.32 \mathrm{~kg}$ respectively.

\subsection{Comparison of the composition and Quantity of Municipal Solid Waste from Different Sources}

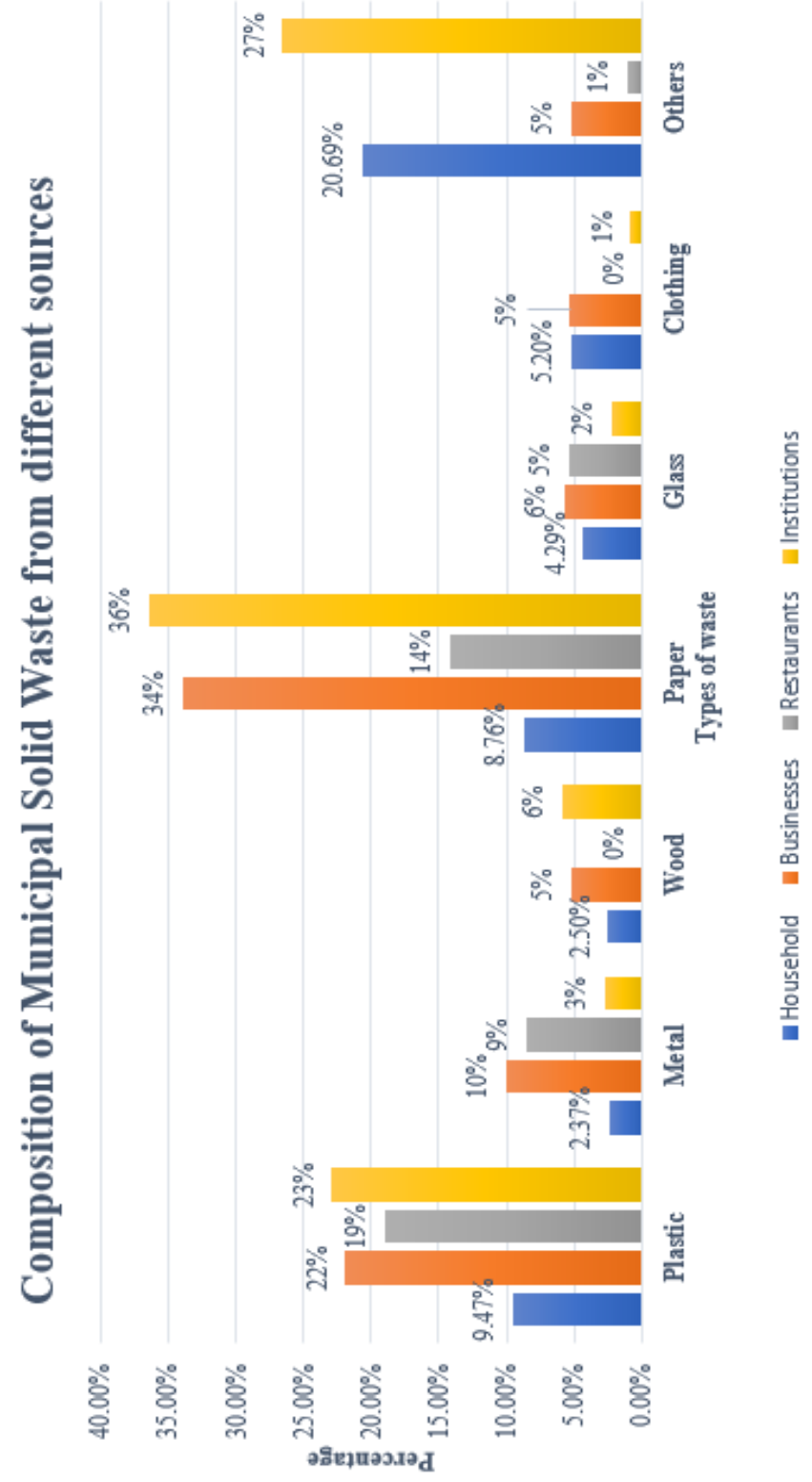

Fig.4.9.1 Comparison of the composition and Quantity of Municipal Solid Waste from Different Sources.

As per the figure it was clear that highest contribution to waste was paper and kitchen waste or food waste. Kitchen waste was highest from household and restaurants while, paper waste was the highest from businesses and institutions.

Although kitchen waste and paper were having highest composition per source, from institutions and businesses, when considering the all the sources the waste of "others" was the second most common type of waste by weight. The kitchen waste from the houses was recorded as $5,256.94 \mathrm{~kg} /$ day, while kitchen waste was recorded as $2,328 \mathrm{~kg}$. The third highest category of waste was plastic wastes from house hold with $1,065.92 \mathrm{~kg}$. This category 
was followed by paper waste from households and businesses with $985.80 \mathrm{~kg}$ and $952.43 \mathrm{~kg}$ respectively.

The total municipal solid waste was found out to be consisting of these eight major categories, Plastic, Metal, Wood, Paper, Glass, Kitchen / Food waste, clothing and others. 39 percentage of the total was kitchen waste, while others waste second highest with 17 percentage of the total waste. About 64.71 percent of the others category was biodegradable waste containing dry leaves, fish wastes, garden waste, diapers. The remaining 35.29 percentage of the others contains tires and ash which was nonbiodegradable. 68 percent of the total municipal solid waste generated in Kulhudhuffushi was biodegradable was. Only 32 percent of waste was non-biodegradable. Therefore, from the $15,462.70 \mathrm{~kg}$ (15.46 tonnes) of municipal solid was generated in Kulhudhuffushi $10,514.64 \mathrm{~kg}$ of waste was biodegradable waste. Only $4948.06 \mathrm{~kg}$ (4.95 tonnes of waste were non-biodegradable. Kulhudhuffushi generates a total of $5,643,885.5 \mathrm{~kg}$ $(5,643.89$ tonnes) of municipal solid waste on a yearly basis. With a population of just under 10 thousand people, the municipal solid waste generation of the town was about $1.13-1.55 \mathrm{~kg}$ per capita per day. A study conducted in New York was proven the municipal solid waste generation per capita was $1.5 \mathrm{~kg}$ per capita per day. [5] When a yearlong management plan was to be considered $3,837,842.14 \mathrm{~kg}$ (3,837.84 tonnes) of waste was to be biodegraded and the remaining $1,806,043.36 \mathrm{~kg}(1,806.04$ tonnes) of waste was non-biodegraded.

\subsection{Current Waste Collection}

The current waste collection system of the town of Kulhudhuffushi is one key aspect to be upgraded in order to upgrade the whole waste management system of the town. Furthermore, collection sums up to cost two-third of the total cost of waste disposal. [3] 93 percent of the surveyed population was not satisfied with the current method of waste collection. There were few concerns which was highlighted by a number of households. As a primary concern, 38.08 percent of the people wants to increase the frequency of the waste collection. From the figure below, it is clear that 68.2 percent of the population dispose waste on weekly basis as the collection service scheduled only once a week.

A small percentage of 28.3 disposes the waste on a regular basis. As a secondary concern, a large group of the surveyed population believes that waste categorization was one of the main areas to be made better in order to provide a better waste collection. Source infect can reduce the cost of separation by manual or mechanical sorting, hence reducing the expenses on some aspects to focus on more needed aspects. [5] Furthermore, 16.15 percent of the surveyed house hold was recommending to upgrade the current collection vehicles. The general public was concerned as the types of vehicles currently used for was collection were just normal lorries and pickups. In addition, the general public recommends dustbins in public areas such as market places, parks and beaches so that waste generated on those area would not pollute the environment. These public dustbins could be handled by the collection crew as part of their routine.

\subsection{Current Waste Management System}

The current method of waste disposal was open burning. [7] Which intern caused a great deal of risk to the general public living near close vicinity of the dump site. Furthermore, the current handler of dumpsite, was concerned that the open burning incidents was not generated by the handler but the trespassing public. Fenaka corporation further added that open burning of local towns was prohibited under the waste management regulation of Maldives and thereby, was not taking part in any such activities. [8] No matter the origination of open burning, improper burning was highly dangerous to both people and to the environment. [9] Due to such concerns the $94.6 \%$ of the general public was not satisfied with the current method of waste management in Kulhudhuffushi.

\subsection{Existing Trends and Future Contribution of General Public to Improve the Solid Waste Management}

In this research it was proven that $93.8 \%$ of the people was disposing the waste to the dumpsite although $6.2 \%$ of the people chose other areas of the town to get rid of the waste. Disposing the waste to areas with in the town except the areas specifically allocated for was an offence punishable by law as per the waste management regulation. However, illegal dumping of waste was observed by 75.6 percent of the sample being surveyed in this research. Moreover, the locations of most illegal waste disposal include the lake area and beach with 37.31 percent and 33.85 percent respectively of the total illegal dumping. The main reason for illegal dumping was not having a proper penalty to the parties who go illegal dumping. Penalties were mentioned in the waste management regulation regarding illegal dumping of waste. However, the enforcement of these rules and regulations were not practice.

$78.3 \%$ of the people was paying up to 100 Maldivian Rufiyaa per month on waste collection. Also, it was observed that $54.3 \%$ of the people were willing to pay a contribution between 101 - 200 Maldivian Rufiyaa. 
Further $28.4 \%$ was even willing to contribute up to 300 Maldivian Rufiyaa for the better waste management system.

\subsection{Volume of The Solid Waste}

\begin{tabular}{|c|c|c|c|c|}
\hline Component & $\begin{array}{c}\text { Typical Density } \\
(\mathrm{kg} / \mathrm{m} 3)\end{array}$ & $\begin{array}{c}\text { Mass of solid } \\
\text { waste per day } \\
\text { (Kg) }\end{array}$ & $\begin{array}{c}\text { Volume of } \\
\text { Solid Waste } \\
\text { per day }\left(\mathbf{m}^{3}\right)\end{array}$ & $\begin{array}{c}\text { Volume of } \\
\text { Solid Waste per } \\
\text { day }\left(\mathrm{m}^{3}\right)\end{array}$ \\
\hline Plastic & 60 & 1975,78 & 32.93 & $12,019,45$ \\
\hline Metal & 350 & 624.72 & 1.78 & 649.7 \\
\hline Wood & 230 & 470.41 & 2.05 & 748.25 \\
\hline Paper & 90 & $2,300.69$ & 25.56 & $9,329.4$ \\
\hline Glass & 200 & 697.65 & 3.49 & $1,273.85$ \\
\hline $\begin{array}{l}\text { Kitchen Waste } \\
\text { Food Waste }\end{array}$ & 300 & $5,977.89$ & 19.93 & 7.274 .45 \\
\hline Clothing & 60 & 740.62 & 12.3 & 4.489 .5 \\
\hline Garden Waste & 100 & 2.674 .94 & 26.75 & $9,763,75$ \\
\hline \multicolumn{3}{|c|}{ TOTAL } & 124.83 & $45,548.35$ \\
\hline
\end{tabular}

Fig.4.13.1 Volume of Slid Waste

\subsection{Number of Trips and Number of Trucks}

There should be 4 rear loader trucks to collected all the bio degradable was and four multi compartment trucks to collect all the non-bio-degradable waste. With the multi compartment collection trucks multiple types of waste can be separately collected. Further 2 Trucks should be kept to collect waste from public dustbins and on call waste collection orders. Hence, the total number of was collection vehicles.

\subsection{Storage Facility for Non-Biodegradable Waste}

Non-biodegradable waste could be compacted and stored in the dumpsite and transferred to an incineration facility managed my Waste Management Corporation (WAMCO) on a specific time schedule. Total volume of the nonbiodegradable waste coming to the dumpsite was $(50.5 \mathrm{~m} 3$ daily) $18,432.5 \mathrm{~m} 3$. On the yearly waste generation of 5,643 tonnes of waste $1,805.76$ tonnes were nonbiodegradable. Hence, the 450Tonne landing craft can remove the non-biodegradable waste from Kulhudhuffushi on a quarterly basis per year (four times per year). Therefore, at a given time the maximum amount of nonbiodegradable waste present in the Kulhudhuffushi dump site would be 451.44 tonnes $(3,646.75 \mathrm{~m} 3)$. Therefore, $4 \mathrm{~m}$ x $4 \mathrm{~m} \times 150 \mathrm{~m}$, two storage bunkers can store the waste until it can be transported from the town.

For biodegradable waste, composting plant would be the most suitable method. Due to the high amount of moisture content incineration would not be a suitable option for biodegradable waste. $98 \%$ of the moisture of the total municipal solid waste of Kulhudhuffushi was from biodegradable waste. Non-biodegradable waste only contains $2 \%$ of the total moisture, hence making them ideal for incineration. Mechanical composting was the preferred choice for the town of Kulhudhuffushi as the land area does not give provision to establish an open composting facility. Furthermore, mechanical composting can reduce the stabilization time of compost from 5 weeks to 1 week increasing the rate of production and hence the time period waste has to be handled. [4]

\section{FUTURE DIRECTIONS}

With the development and technological advancement, as well as the population increase could alter the current composition of municipal solid waste in Kulhudhuffushi. For the purpose of this research only collection, transfer, transport and disposal were focused. However, the approach of energy recovery can also be would also be beneficial as the level of energy consumption was forecasted to increase with time due to development.

Furthermore, with the construction and demolition waste was not much of a concern. With the advancement in construction industry and introduction of multi-storey buildings such waste types might not be disposable through the current method of disposal.

In addition, the journey of the non-biodegradable waste from Kulhudhuffushi to the incineration plant was a long journey. Hence, a closer, centralized waste management town could be a future approach, which would not only include waste solutions for Kulhudhuffushi but to the whole "Thiladhunmathi" atoll.

\section{CONCLUSION}

The research conducted on the topic Solid waste management in Kulhudhuffushi; most suitable solutions for the crisis was specifically focus on the context of the town of Haa Dhaal Atoll Kulhudhuffushi. For a proper decision of a waste management solution the composition and quantities of the waste generation on a daily basis was a necessity. However, the dump site handler of Kulhudhuffushi was not maintaining any record or data.

Therefore, the daily waste generation from four main sources was measured through questionnaire survey. The four main waste generation sources in Kulhudhuffushi includes, household, businesses, restaurants and institutions. For each type of source, the daily weight of waste generation was measured along with the composition of different types of waste materials. On average a single household generates $7.58 \mathrm{~kg}$ of waste, while a business outlet was generating $13.75 \mathrm{~kg}$ per day. Restaurants and institutions generate $48 \mathrm{~kg}$ and $38.58 \mathrm{~kg}$ of waste on a daily basis. It was found that the highest composition of municipal solids waste was kitchen/food waste from household and restaurants with $47.72 \%$ and $52 \%$ respectively. The second highest composition of solid 
waste was paper waste from businesses and institutions with $34 \%$ and $36 \%$ respectively.

The weight of solid waste generation from all the sources reaches to 5,643 tonnes per year. Among which the highest contribution was from the households with 4,107 tonnes per year. Business establishments generates 1,023 tonnes of waste on a yearly basis. The proportion of restaurants and institutions was quiet less as the number of units were less in those sources. However, restaurants and institutions were measured to generate 245 and 267 tonnes of waste every year. The largest amount of municipal solid waste was kitchen waste with a total of 2,181 tonnes per year from all sources combine.

Furthermore, $68 \%$ of the total municipal solid waste generated on the Kulhudhuffushi is Biodegradable while only $32 \%$ of the waste was non-biodegradable. Due to the high portion of biodegradable waste $98 \%$ of total moisture content was in biodegradable waste (moisture content of 1,979 tonnes). As a result, the process of incineration was not the most suitable solution to dispose the solid waste is Kulhudhuffushi. With $68 \%$ of biodegradable waste disposal by composting was the preferred option for Kulhudhuffushi. However, due to the limitation of land area, open composting was ruled out and mechanical composting is the most suitable solution for the solid waste issue of Kulhudhuffushi. Mechanical composting further reduces the compost settlement type by five times, hence was an added benefit. Hence, the objective of proposing the most suitable waste disposal solution was achieved.

The collection of waste from Kulhudhuffushi was to be conducted by zoning the town in to three areas. Each area was be collected twice a week (the survey suggested that the people of Kulhudhuffushi preferred to increase the collection frequency, hence it could be achieved) on doorto-door collection process. A total 10 dump trucks with $2 \mathrm{~m} 3$ was preferred for smooth operations. Rear loader type 6 trucks were to be involved in collection process. 4 trucks in the door-to-door collection of biodegradable waste and 2 trucks in the on-call collection. The remaining 4 trucks would be on multiple compartment so collection of nonbiodegradable waste. Hence, the objective of proposing a suitable collection method was achieved. In addition to the dump trucks Front end loaders, motor grader, earth movers and steel wheeled compactors were also requirement to maintain the site. The non-biodegradable portion of the waste (1805.76 tonnes per year) would be stored in $4 \mathrm{~m} \mathrm{x}$ $4 \mathrm{~m} \mathrm{x} 150 \mathrm{~m}$ two storage bunkers which would be transferred to the WAMCO incineration plant on quarterly basis per year. Thereby, achieving the third objective of this research project.

Furthermore, the smooth functioning of this method would be achieved when waste was categorized from the sources (source separation). 38.08\% of the surveyed population was found to be forwarding the opinion. Moreover, $54.3 \%$ was found to be willing to contribute to a better waste management system. As a result, the proper payment scheme should be implemented to maintain a source of income for the maintenance and proper functioning of the facility. $55.8 \%$ of the population was engaged in waste reduction from the sources by means of reducing and recycling. Also, the public concerns for the illegal dumping believed the penalties of such offenses should be improved. In addition, the open burning issues were found to be arising not only due to the handler of dumpsite, but due to trespasser as well. Therefore, a proper boundary should be made around the premises of the dumpsite and the accesses control should be fully maintained.

\section{ACKNOWLEDGEMENTS}

First and foremost, I thank the almighty for guiding and assisting me toward success in making this research. Further, I convey my sincere gratitude to my research supervisors Dr. TMWRMB Samarakoon. Without his assistance and dedicated involvement in every step throughout the process, this research would have never been accomplished. Moreover, I would like to convey my appreciation to the Head of Department of Civil Engineering Dr. NK Gunasekara and Dean Faculty of Engineering Dr. WCDK Fernando.

Getting through my dissertation required more than academic support. I cannot begin to express my gratitude and appreciation for their valuable contribution. Senior members from different institution of Maldives had been unwavering in their personal and professional support during the interview sessions and any other occasion of assistance. Moreover, I would like to appreciate the valued time devoted to my research interviews and questionnaires, by all levels of staffs, official and beloved citizens from all the institutions, businesses, restaurant and households. Furthermore, I would like to convey my gratitude to the all my friends who have help me in distributing questionnaires and collecting data and information for the research works.

Most importantly, I would like to thank my family members specially parents, who offered their encouragement through phone calls and text messages every week - despite our own limited commitment to correspondence. The families support was been kind and supportive to me over the years of my cadetship. This dissertation stands as a testament to my family's unconditional love and encouragement. I apologize to 
anyone, whose name might have been missed from this list. Thank you all for the support throughout this research project.

\section{REFERENCES}

[1] D. Srinivasan, Environmental Engineering, 4th ed. New Delhi: PHI Learning Private Limited, 2015.

[2] Gerard Kiely, Environmental Engineering, 10th ed. New Dhelhi, 2007.

[3] AK Chatterjee, Water Supply, Waste Disposal and Environmental Pollution Engineering (including Odour, Noise \&amp; Air Pollution and its control), 5th ed. New Delhi: Khanna Publishers, 1996.

[4] D. Machenzie L and David A. Cornwell, Introduction to Environmental Engineering, 5th ed. New Delhi: McGraw Hill Education (India) Private Limited, 2014.

[5] Arcadio P. Sincero and Gregoria A. Sincero, Environmental Engineering A Design Approach. .

[6] T. S. Thakkar Sunny A Yadav Bhupendra C Patel Ronak K Shaikh Matin, “' Solid Waste Management By Composting - a Feasibility Study .”" pp. 479-482, 2016.

[7] Arcadio P Sincero \& Gregoria A Sincero, Environmental Engineering A Design Approach, vol. 1. 2010.

[8] "Waste Management Regulation," Dhivehi Sarukaaruge Gaz., vol. 42, no. 113, p. 59, 2013.

[9] "Health and Environmental Effects of Burning Municipal Solid Waste." 